\title{
A CULPABILIDADE CRIMINAL NA PERSPECTIVA DA FILOSOFIA CRISTÃ
}

THE CRIMIN AL GILIT FROM THE PERSPECTIVE OF CHRISTLAN PHILOSOPHY

\author{
Altamir Francisco da Silva ${ }^{1}$ \\ Faculdade Damas \\ Ana Paula Lessa ${ }^{2}$ \\ Faculdade Damas
}

\section{Resumo}

A culpabilidade é o único elemento do crime que tem por objeto o homem. Investigar as relações entre ela e filosofia cristã é o objeto desse artigo.

Palavras-chave

Culpabilidade. Liberdade. Cristianismo.

\section{Abstract}

Guilt is the only element of crime that has as its object man. Investigating the relations between it and Christian philosophy is the object of this article.

Keywords

Guilt. Freedom. Christianity.

\section{INTRODUÇÃO}

A ideia de homem livre construída ao longo do tempo possui inegáveis raízes filosófico-cristãs. A partir da premissa de que o homem é fruto da criação divina, o pensamento cristão, sem nenhuma sombra de dúvidas, influenciou decisivamente os inúmeros ramos do saber. Particularmente, no presente estudo, busca-se reconhecer os traços, ora marcantes do pensamento cristão na formação da culpabilidade penal. Considerando que a aplicação da pena é a consequência imediata da análise

\footnotetext{
${ }^{1}$ Doutor Pelo Pontifício Instituo Marianum - Roma. Professor do Programa de Pósgraduação em Direito da Faculdade Damas da Instrução Cristã 2 Mestre em Direito pela Faculdade Damas da Instrução Cristã
} 
da culpabilidade do indivíduo, é imprescindível a compreensão e o estudo das ideias que nortearam a construção do referido instituto.

Vale ressaltar que, embora o termo culpabilidade tenha surgido com Franz Von Liszt, o gérmen da culpabilidade pode ser percebido na responsabilidade penal fundada na responsabilidade moral concebida por Carrara. No entanto, embora tais ideias que foram construídas em tempo remoto, possam sugerir a um apressado leitor que já foram superadas, resta a impressão de que elas, de alguma forma, ainda persistem na atualidade.

O trabalho em comento possui como objetivo realizar a conexão entre o passado e o presente das ideias penais tendo como fio condutor o livre arbítrio. A partir da Escola Clássica de Carrara serão analisadas as diferenças e possíveis semelhanças entre a concepção de liberdade de ação em Carrara e a atual noção de liberdade de ação, procurando demonstrar a influência da filosofia cristã na formação desse instituto tão caro ao direito penal, não apenas pela sua importância para a construção dogmática, mas, acima de tudo, devido ao papel garantidor da dignidade do homem. Enxergar o homem como ser eminentemente livre, para além de conceder a este homem a possibilidade de dominar a si mesmo, é reconhecer o ser humano como alguém dotado da capacidade de ser autor da sua própria história.

A culpabilidade, dentre os elementos do delito, é o único elemento que se volta para a análise da conduta humana, para o ser humano. Os outros elementos do delito são construídos a partir da análise do fato, no entanto, apenas a culpabilidade requer um olhar acurado sobre o autor do fato, sobre o homem que pratica uma conduta delituosa.

A ideia contemporânea de culpabilidade foi construída paulatinamente, inserida nos mais variados contextos históricos. Seja como elemento do delito ou ainda como princípio regulador da aplicação da pena, dentre muitas incertezas, a grande certeza reside na importância desse instituto para o Estado Democrático de Direito e, principalmente, para o cidadão que, diante da prática de um ilícito, será julgado e condenado, 
pretensamente, a partir da dogmática estatuída sobre a culpabilidade. Destarte, diante do poder punitivo estatal, impende prezar pelas garantias fundamentais, assim como pela racionalização da punição.

\section{BREVES CONSIDERAÇÕES SOBRE O DILEMA FILSÓFICO EM TORNO DO LIVRE ARBÍTRIO E SUA TRANSCENDÊNCIA JURÍDICO-PENAL}

Antes de se analisar a concepção da Escolas Clássica acerca do livre arbítrio e sua inserção na reponsabilidade penal, gérmen da culpabilidade, impende fazer algumas poucas considerações sobre a discussão envolvendo o livre arbítrio e o determinismo, um debate que ultrapassa a questão jurídico-penal que, para além de ser um problema jurídico, consiste numa questão metafísica acolhida pelo Direito para fundamentar seus institutos legais. Para tanto, faz-se necessário tecer algumas palavras com o intuito de conceituar e situar o problema que se deseja enfrentar com a pesquisa em comento.

Inicialmente, para a devida contextualização da problemática e a sua correta compreensão, impende ressaltar que a expressão livre arbítrio possui uma inegável origem de cunho filosófico e religioso e está no centro da ideia de indeterminismo absoluto, conforme Busato $^{3}$, o que fundamenta a concepção de culpabilidade e remete a uma perceptível raiz religiosa. Seguindo o pensamento do citado autor, o homem livre que atua de maneira consciente pode ser responsabilizado pelos seus atos gerando uma associação culpabilidade/pena e pecado/penitência. A religião influencia, dessa forma, inclusive, nos termos utilizados, numa clara analogia entre pecado e culpa, pena e penitência.

${ }^{3}$ BUSATO, Paulo Cesar. Neurociência e direito penal. São Paulo: Atlas, 2014, p. 57. 
No mesmo sentir, consoante Carvalho ${ }^{4}$, desde as concepções de culpa nas culturas judaico-cristãs, o castigo infringido foi legitimado, dando origem, dessa forma, ao poder punitivo estatal numa gradual solidificação do vínculo entre crime e castigo, culpa e pena. Ao estabelecer essa possibilidade de atribuição de culpa ao sujeito livre, a racionalização do poder punitivo pelo Estado moderno se solidifica.

De acordo com Brandão ${ }^{5}$, os pensadores cristãos contribuíram valiosa e decisivamente para a elaboração da ideia de dignidade humana, postulado que permanece inabalável, um verdadeiro alicerce do Direito em todas as suas vertentes. O homem do cristianismo é um ser valioso por si mesmo, valor que brota da sua imanência divina, decorre do seu lugar na criação, fruto da obra mais preciosa do criador. No entanto, imprescindível considerar, que, embora a dignidade tenha sido exaltada pelos filósofos cristãos, na prática, a igreja católica nem sempre atuou em consonância com o seu discurso, certamente, devido aos interesses políticos existentes que obstavam tal prática.

Segundo Vives Antón", a expressão "livre arbítrio" como significado de liberdade remete ao pensamento escolástico ancorado na ideia de substância espiritual fragmentada em potências, dentre as quais, a liberdade seria uma das potências considerada livre, determinando-se de forma plena, sem qualquer obstáculo para sua manifestação, pensamento que considera superado e insustentável sob a perspectiva do Direito.

No entanto, aproveitando as palavras de Vives Antón ${ }^{7}$ e a atualidade das suas ideias no cenário da dogmática penal, ainda que o livre arbítrio da forma idealizada pelos escolásticos, no sentir do citado autor, não encontre

\footnotetext{
4 CARVALHO, Salo de. Penas e medidas de segurança no direito penal brasileiro: fundamentos e aplicação judicial. São Paulo: Saraiva, 2013, p. 169.

${ }^{5}$ BRANDÃO, Cláudio. Teoria Jurídica do Crime. $4^{a}$ Ed. Vol. 1, São Paulo: Atlas, 2015, p. 116.

${ }^{6}$ VIVES ANTÓN, Tomás S. Fundamentos del Sistema Penal. Valencia: Tirant Lo Blanch, 1996 , p. 314.

${ }^{7}$ Idem, p. 314.
} 
agasalho no direito penal contemporâneo, faz-se necessário pontuar o grandioso legado dos escolásticos e de tantos outros filósofos cristãos.

Conforme Arendt ${ }^{8}$, a liberdade era apenas um conceito político na antiguidade grega, bem como na romana, prescindindo, assim, da faculdade de vontade. Sendo assim, apenas quando os cristãos primitivos, particularmente, Paulo, fizeram referência a uma liberdade que não tinha relação com a política foi que o conceito de liberdade pôde adentrar na história

da filosofia. Se Paulo foi o primeiro a exaltar a liberdade de vontade, Agostinho foi o mais importante filósofo desta faculdade humana. Dessa forma, a tradição cristã influenciou decisivamente a história do problema da liberdade, considerando que, a todo instante, automaticamente, a ideia de liberdade se confunde com livre arbítrio.

A liberdade tornou-se um dos problemas principais da filosofia quando foi vivenciada como alguma coisa que ocorria no relacionamento entre mim e mim mesmo, fora do relacionamento entre os homens. Livre arbítrio e liberdade de noções tornam-se sinônimos, e a presença da liberdade era vivenciada em completa solidão, onde nenhum homem pudesse obstar a ardente contenda que tinha lugar... na "morada interior" da alma e na escura "câmara do coração"”.

Portanto, nas lições de $A_{r}$ ndt $^{10}$, o problema da vontade e, consequentemente, da liberdade de vontade possui origem histórica na teologia onde a liberdade era sinônimo do querer como um dado da consciência ou do espírito.

\footnotetext{
8 ARENDT, Hannah. Que é liberdade? In: Entre o passado e o futuro. 2. Ed. São Paulo: Perspectiva, 1972, p. 204.

${ }_{9}^{9}$ ARENDT, Hannah. Que é liberdade? In: Entre o passado e o futuro. 2. Ed. São Paulo: Perspectiva, 1972, p. 205.

10 ARENDT, Hannah. A Vida do Espírito. $4^{\text {a }}$ Ed. Rio de Janeiro: Relume Dumará, 2000, p. 200.
} 
No entanto, impende ressaltar que Arendt ${ }^{11}$, ao discorrer sobre liberdade, separa conceitualmente duas acepções distintas situando historicamente no tempo o sentido de cada uma delas. Primeiramente, como fruto da construção dos pensadores, faz referência a liberdade filosófica que consiste no exercício da vontade, relevante apenas para aqueles que vivem fora das comunidades políticas como indivíduos solitários. De outra forma, a liberdade enquanto poder decorrente da ação no mundo foi denominada pela autora como liberdade política, condição atribuída ao cidadão, ideia dominante na antiguidade antes de Cristo. Enquanto a liberdade filosófica era um simples atributo da condição humana, de qualquer homem, a liberdade política vinculava-se ao sentimento de pertença do homem a sociedade e ao seu papel de cidadão por meio das relações sociais reguladas pelas leis e costumes. "A liberdade política só é possível na esfera da pluralidade humana"12, não sendo, portanto, uma ação solitária do pensamento.

Dos pensadores escolásticos emergiu uma filosofia profícua que, seria impossível analisar em um simples trabalho, ademais, não consiste no objeto de pesquisa desse presente estudo. No entanto, dentre os filósofos cristãos, merecem destaque as ideias de Agostinho ${ }^{13}$. O homem idealizado por Agostinho ${ }^{14}$, enquanto criatura divina concebida à imagem e semelhança de seu criador, era dotado do livre arbítrio desde a sua concepção. O ser humano criado por Deus estava configurado, na sua mais profunda essência, a exercer a faculdade de eleição e por isso, não poderia ser considerado como um ser determinado por quaisquer influências, mas, possuidor da faculdade da vontade, o livre arbítrio.

De acordo com Arendt ${ }^{15}$, Santo Agostinho identifica a criação do homem com o começo de tudo para conceder ao tempo a ideia de

\footnotetext{
${ }^{11}$ Idem, p. 336.

12 Ibidem.

13 AGOSTINHO, Santo. O Livre-arbítrio. São Paulo: Paulus, 1995.

${ }^{14}$ Idem.

${ }^{15}$ ARENDT, Hannah. A Vida do Espírito. $4^{\text {a }}$ Ed. Rio de Janeiro: Relume Dumará, 2000, p. 266.
} 
retilinearidade e para contestar a concepção cíclica de tempo dos gregos, concepção esta da antiguidade grega que impediria o surgimento da novidade, fruto da vontade. Dessa forma, o filósofo cristão assegura que a vontade pertence a individualidade do homem enquanto criação única e irrepetível no mundo. Portanto, a vontade adquire uma feição em Agostinho, a despeito de ter sido outrora ignorada pelos gregos, feição que frutifica a partir da nova conceituação do tempo.

Conforme Agostinho ${ }^{16}$, o pecado era fruto das escolhas más do homem, que, ao se deixar dominar pelos seus instintos e paixões, tornavase um mero escravo das indesejadas inclinações. De outra forma, se o homem optava pelo caminho da virtude ele alcançava o máximo de liberdade, assumindo a condição de homem livre para a qual foi criado.

Zaffaroni $^{17}$, ainda que não se sinta atraído pelo pensamento jus naturalista, de acordo com suas próprias palavras, adverte acerca da impossibilidade de negar a pertença da natureza do direito à natureza humana. O Direito deve, portanto, servir ao homem e não o homem ao Direito. Por essa perspectiva, ainda que a ciência jurídica procure se divorciar da filosofia, continua sendo uma ciência filosófica, ou ainda que queira se desvencilhar da ética, nem por isso deixa de ser uma ciência moral. Obviamente, as valorações jurídicas sofrem as variações inevitáveis do transcurso natural do tempo, conforme as concepções filosóficas de determinado momento.

Fazendo um claro contraponto ao ideário indeterminista, Schopenhauer $^{18}$ acredita que o homem, assim como os objetos da experiência, consiste num fenômeno no espaço e no tempo. Sendo assim, se as leis da causalidade valem para todos os fenômenos, certamente deverão ser aplicadas ao ser humano. Portanto, acreditar no livre arbítrio

\footnotetext{
16 AGOSTINHO, Santo. O Livre-arbítrio. São Paulo: Paulus, 1995.

${ }^{17}$ ZAFFARONI, Eugenio Raúl. Navegando Laberintos. Escritos Jurídicos. Buenos Aires: Hammurabi, 2014, p. 116.

${ }^{18}$ SCHOPENHAUER, Arthur. O Livre-arbítrio. Rio de Janeiro: Nova Fronteira, 2012, p.p. 74-75.
} 
conduz a aceitação das ações humanas como verdadeiros milagres tal qual os efeitos sem causas. Somente "filosofeiros sem miolos" poderiam desejar encontrar a prova do livre arbítrio.

Segundo Zaffaroni ${ }^{19}$, em 1787, nos anos que antecederam a revolução francesa, o indeterminismo foi duramente criticado por Roudeau, que, a partir das ideias deterministas, considerava o delinquente como um ser enfermo, necessitando assim de tratamento hospitalar no lugar de penas de prisão. Para tanto, as prisões deveriam ser convertidas em hospitais numa soma de esforços da sociedade para promover o amparo necessário ao homem delinquente.

Nas lições do autor acima ${ }^{20}$, Pedro Garcia Dorado Montero, um século depois, seguindo o ideário determinista, construiu seu pensamento baseado na negação da imputabilidade e da responsabilidade moral, de forma similar aquilo que Roundeau instituiu.

Por conseguinte, ainda que haja um vasto universo de ideias que refutam o indeterminismo, conforme Zaffaroni ${ }^{21}$, Rondeau e Dorado são considerados os deterministas mais coerentes com a sua postura. Porquanto, para eles, se o homem não pode decidir de forma livre por ser essencialmente determinado e, dessa forma, a sua conduta for resultado de um conjunto de forças que agem a despeito da sua vontade e liberdade, por conseguinte, não haverá responsabilidade a ser-lhe atribuída como fruto de suas ações.

Conforme Anitua ${ }^{22}$, para Pedro Dorado Montero, se o homem está determinado a agir de certo modo, ainda que contrariamente ao instituído pela sociedade, não haverá sentido em atribuir-lhe reponsabilidade por tais

19 ZAFFARONI, Eugenio Raúl. Navegando Laberintos. Escritos Jurídicos. Buenos Aires: Hammurabi, 2014, p. 118.

${ }^{20}$ Idem, p. 119.

${ }^{21}$ Ibidem, p. 120.

22 ANITUA, Gabriel Ignacio. História dos Pensamentos Criminológicos. Rio de Janeiro: Revan, 2008, pp. 326-327. 
atos. De acordo com o pensamento de Dorado, o delito não passa de uma "criação política", instituída e firmada pela teia social, de onde surge a necessidade de proteger o delinquente por meio da correção. Dessa forma, consoante o determinismo de Dorado, o direito penal deveria abandonar sua função repressiva convertendo-se num instrumento preventivo do delito. Para tanto, os juízes e policiais dariam lugar aos médicos e pedagogos. Ao invés de infringir castigos com a aplicação de penas, haveria uma atribuição dada a sociedade para cumprir sua função, qual seja, a de recuperar os desgarrados, verdadeiros transgressores sociais.

Para Zaffaroni ${ }^{23}$, outra corrente de ideias gerada no seio determinista foi o positivismo penal fruto das ideias de Moleschott a partir de um direito de defesa social. Conforme o referido pensamento, essa vertente determinista baseava-se na responsabilidade recíproca entre a sociedade e o indivíduo. Sendo assim, a relação se daria por meio do determinismo do sujeito que está destinado a tornar-se um ser prejudicial a sociedade e, por sua vez, ao determinismo da sociedade chamada a defender-se da ofensividade do indivíduo perigoso.

Ainda que haja uma diversidade de posicionamentos em torno da discussão travada entre o livre arbítrio e o determinismo, inclusive, sendo considerada por alguns uma discussão dispensável ao Direito, procurando isolar o Direito da Filosofia, no sentir de Zaffaronii ${ }^{24}$, o indeterminismo, ainda que não seja absoluto, pode ser considerado como algo imprescindível ao direito penal, não sendo possível ao Direito, subsistir à ausência da filosofia.

Portanto, conforme o discorrido acima, dentre os problemas filosóficos que cercam o Direito, a liberdade de vontade pode ser considerada como a sombra que persegue o caminhante, embora presente, não pode ser aprisionada, tocada, e por isso, o referido problema segue

${ }^{23}$ ZAFFARONI, Eugenio Raúl. Navegando Laberintos. Escritos Juridicos. Buenos Aires: Hammurabi, 2014, p. 120.

${ }^{24}$ Idem, p. 127-137. 
insolúvel, por não poder ser demonstrada empiricamente. Talvez seja esse o seu fascínio, a sua essência presumivelmente inatingível, inacessível, oculta à inteligência humana, que, ao longo do tempo motivou as mais diferentes elaborações conceituais.

A partir das colocações realizadas, reafirmando a antiga discussão que envolve a ideia de liberdade e o seu lugar na teoria jurídico-penal, será abordada, de forma bastante sucinta, a construção doutrinária da responsabilidade penal da Escola clássica e sua importância para a dogmática penal na construção da culpabilidade.

\section{ESCOLA CLÁSSICA: O LIVRE ARBÍTRIO COMO MARCO DEFINIDOR DA CONSTRUÇÃO DA RESPONSABILIDADE PENAL}

De acordo com Moniz Sodré ${ }^{25}$, para a escola clássica, a responsabilidade penal do criminoso possui seu fundamento na responsabilidade moral que está ancorada no livre arbítrio, faculdade intrínseca da alma humana. Portanto, para que haja a responsabilidade moral, faz-se necessário a inteligência e o livre arbítrio. Apenas através do conhecimento da lei moral somado à capacidade de observá-la, o homem pode ser responsabilizado legalmente.

Ainda conforme o autor, o livre arbítrio conduz a crença de que depende da simples vontade do indivíduo, diante das pressões do meio exterior e das suas oscilações internas, decidir entre duas possibilidades opostas. Dessa forma:

Os livre arbitristas têm comparado a alma a uma balança que, possuindo nos pratos os motivos das ações, tivesse o poder

\footnotetext{
25 MONIZ SODRÉ, Antonio. As Três Escolas Penais: Clássica, Antropológica e Crítica (estudo comparativo). Rio de Janeiro: Freitas Bastos, 1968, p. 69.
} 
de, determinando a si mesma, independente da lei da gravidade, fazer subir o prato onde houvesse maior peso, razões mais poderosas ou motivos mais fortes ${ }^{26}$.

Os criminalistas clássicos acreditam que o livre arbítrio é atributo de todos os homens psiquicamente desenvolvidos e com mentes saudáveis. Sendo assim, são responsáveis moralmente por seus atos, frutos de uma vontade livre e soberana.

Considerando que a liberdade moral serve de esteio para a responsabilidade moral, nasce assim o primeiro princípio básico da escola clássica, qual seja, "o homem possui o livre arbítrio e por isso é moralmente culpado e legalmente responsável por seus delitos", nas palavras de Moniz Sodré $^{27}$, e, por isso, o delito decorre exclusivamente da vontade livre do delinquente.

Francesco Carrara pode ser considerado o mais importante representante dos ideais clássicos e, em sua obra, Carrara ${ }^{28}$ define o delito como uma infração à lei do Estado, promulgada para resguardar a segurança dos cidadãos, resultado de um ato externo do homem, positivo ou negativo e moralmente imputável.

Ainda que Carrara faça referência a três tipos de leis, ele prossegue dando ênfase à lei civil. São as leis civis que interessam ao Direito quanto à sua devida observância. As leis morais são reveladas ao homem pela consciência, as leis religiosas são reveladas por Deus, e as leis civis, para assim se tornarem, necessitam de promulgação para que sejam exigidas dos cidadãos. Considerando que os direitos dos homens não são lesionados através de atos internos, o pensamento, o desejo, o projeto e a determinação não possuem relevância enquanto não são praticados. Dessa forma, é

\footnotetext{
${ }^{26}$ MONIZ SODRÉ, Antonio. As Três Escolas Penais: Clássica, Antropológica e Crítica (estudo comparativo). Rio de Janeiro: Freitas Bastos, 1968, p. 69. 50 Idem, p. 71.

${ }^{27}$ Idem, p. 73.

${ }^{28}$ CARRARA, Francesco. Programa del Curso de Derecho Criminal: Parte General, Tomo I. San Jose/Costa Rica: Tipografia Nacional, 1889, p.p. 34-52.
} 
necessária uma ação qualificada como contrária a lei civil para que haja repercussões na esfera jurídica.

Conforme a formulação do conceito de delito elaborada por Francesco Carrara, apenas o homem, enquanto o único entre todos os seres criados e dotados de uma vontade racional e suscetível de direção, pode ser o sujeito ativo do delito. Portanto, o livre arbítrio se constitui num pressuposto filosófico no qual se assenta a ideia de Carrara, sendo dispensável e desnecessária a discussão acerca da sua existência ou não.

Seguindo as lições do autor italiano, o delito resulta de um conflito entre um ato humano e um direito estabelecido, sendo fruto de um concurso de forças inerentes a natureza humana. $\mathrm{O}$ ato humano que pode ser caracterizado como delito, portanto, decorre da força moral e da força física. Enquanto a força física atua por meio do corpo, a força moral se revela pela alma, conforme Carrara ${ }^{29}$.

A força moral consiste no próprio caráter moral da ação, sendo quatro as qualificações internas que concorrem para a externalização da ação. O conhecimento da lei e a previsão dos efeitos são duas das condições vinculadas ao concurso da inteligência, enquanto a liberdade de escolher e a vontade de atuar estão estreitamente conectadas ao concurso de vontade. Dos concursos da inteligência e da vontade resulta a intenção que pode ser definida como a vontade direcionada a um fim.

De outra forma, a força física decorre da externalização de pensamentos e sentimentos intrínsecos da alma por meio de movimentos corporais, segundo a inclinação para a realização de um ato culpável. Enquanto tais desejos povoam unicamente o universo íntimo do indivíduo, esses sentimentos pertencem unicamente à moral ou à religião, e, portanto, não são consideradas ações físicas. Para que seja uma ação decorrente da força física é imprescindível que haja movimentos corporais destinados a

${ }^{29}$ CARRARA, Francesco. Programa del Curso de Derecho Criminal: Parte General, Tomo I. San Jose/Costa Rica: Tipografia Nacional, 1889, p.p. 60; 166. 
um fim determinado, nas lições de $\operatorname{Carrara}^{30} 58$. Sendo assim, a força física pode ser considerada externa e passiva devido a obediência do corpo à vontade.

Acerca do presente trabalho, impende ressaltar a força moral subjetiva como detentora dos elementos relacionados ao movimento interno do indivíduo, desde a primeira percepção da ideia até a última determinação volitiva. Para que haja a plenitude da força moral subjetiva em um delito, é fundamental que, tanto na percepção, como no juízo, o agente realize uma elaboração interior à luz da inteligência, e em seguida, nos momentos subsequentes, do desejo e da determinação, tenha pleno gozo da sua liberdade.

Ainda segundo o autor acima, responsabilidade social decorre decisivamente da responsabilidade moral. Somente a partir da natureza moral nasce a responsabilidade penal do homem perante uma conduta delituosa, indesejada para a sociedade.

Impende ressaltar, segundo Carrara $^{31}$ que essa pedra angular na qual se ergue o pensamento carrariano encontra-se na concepção cristã de que o homem foi criado à imagem e semelhança divina, sendo, portanto, dotado de uma alma espiritual, rica de inteligência e vontade livre, a obra mais bela de sua divina sabedoria consubstanciada na criação de seres responsáveis por suas próprias ações. Dessa forma, por não estarem submetidos simplesmente a leis físicas, devido à grandiosidade a qual o homem foi elevado ao status de igualdade com seu criador, nasce com a criatura uma lei moral, a lei natural.

Conforme Carrara ${ }^{32}$, graus de delito poderão ser identificados de acordo com as forças moral e física que o compõe. Considerando o elemento moral, a inteligência e a vontade em suas variações, funcionarão como indicativos para a graduação do delito em sua força moral. Dessa

\footnotetext{
${ }^{30}$ CARRARA, Francesco. Programa del Curso de Derecho Criminal: Parte General, Tomo I. San Jose/Costa Rica: Tipografia Nacional, 1889, p. 78.

${ }^{31}$ Idem, p. 08.

32 Ibidem, p. 166.
} 
forma, as circunstâncias que limitam o livre arbítrio do homem, restringindo seu leque de escolhas possibilitam a formação de graus de delito relacionados à vontade. A faculdade de determinar-se, segundo a sua inteligência, preferindo a ação ou a inação fundamenta a liberdade de escolha do homem.

Por conseguinte, a liberdade de escolher como potência abstrata da alma, não pode jamais, ser arrebatada do homem, que, eventualmente, poderá estar numa situação de privação da plenitude do livre arbítrio em virtude de causas internas ou externas que exerçam forte influência sobre o seu espírito, atingindo assim a sua determinação. Dessa forma, há de ser considerada a diminuição de espontaneidade no agente que viola a lei, dado que a força moral resta comprometida na sua essência ou intenção, assim como no resultado da ação.

\section{CONSIDERAÇÕES FINAIS}

Para a filosofia, conforme o presente trabalho, Hannah Arendt, ao fazer referência as ideias de Agostinho, demostra a preciosidade da contribuição do cristianismo para a acepção da ideia de liberdade como produto da vontade humana. Portanto, a filosofia cristã pode ser considerada como o berço da liberdade de vontade ao identificar a criação do homem como começo de tudo, fazendo surgir, dessa forma, a ideia de tempo como algo retilíneo contrariando a concepção cíclica dos gregos. A vontade adquire feição.

Para a dogmática penal, diante das ideias apresentadas, pode ser observado ainda, que, embora, novas doutrinas surjam a cada dia apresentando novos argumentos e fundamentos para a culpabilidade, não consistindo nos mesmos fundamentos outrora apresentados por Carrara, há uma tendência predominante na busca pela preservação da liberdade de vontade como postulado indissociável da dogmática penal. Dessa forma, a magnificência da obra de Carrara ainda reflete luz e brilho por sobre as grandes obras que se seguiram a obra deste memorável italiano. O homem livre, a quem Carrara atribuiu responsabilidade ainda está presente nas 
concepções contemporâneas de culpabilidade que possui inegáveis feições assentadas nas ideias filosófico-cristãs, fortalecendo, portanto, a dignidade da pessoa humana, sustentáculo imprescindível da dogmática penal, indispensável para o Direito.

\section{REFERÊNCIAS}

AGOSTINHO, Santo. O Livre-arbítrio. São Paulo: Paulus, 1995.

ANITUA, Gabriel Ignacio. História dos Pensamentos Criminológicos. Rio de Janeiro: Revan, 2008.

ARENDT, Hannah. Que é liberdade? In: Entre o passado e o futuro. 2. Ed. São Paulo: Perspectiva, 1972.

Dumará, 2000.

A Vida do Espírito. $4^{\mathrm{a}}$ Ed. Rio de Janeiro: Relume

BRANDÃO, Cláudio. Teoria Jurídica do Crime. $4^{\mathrm{a}}$ Ed. Vol. 1, São Paulo: Atlas, 2015.

BUSATO, Paulo Cesar. Neurociência e direito penal. São Paulo: Atlas, 2014.

CARRARA, Francesco. Programa del Curso de Derecho Criminal: Parte General, Tomo I. San Jose/Costa Rica: Tipografia Nacional, 1889.

CARVALHO, Salo de. Penas e medidas de segurança no direito penal brasileiro: fundamentos e aplicação judicial. São Paulo: Saraiva, 2013. 
MONIZ SODRÉ, Antonio. As Três Escolas Penais: Clássica, Antropológica e Crítica (estudo comparativo). Rio de Janeiro: Freitas Bastos, 1968.

SCHOPENHAUER, Arthur. O Livre-arbítrio. Rio de Janeiro: Nova Fronteira, 2012.

VIVES ANTÓN, Tomás S. Fundamentos del Sistema Penal. Valencia: Tirant Lo Blanch, 1996.

ZAFFARONI, Eugenio Raúl. Navegando Laberintos. Escritos Jurídicos. Buenos Aires: Hammurabi. 